Available online at https://jurnal.stmikroyal.ac.id/index.php/jurdimas

\title{
DETEKSI DINI FAKTOR RESIKO DIABETES MELLITUS DI DUSUN KALANGAN KECAMATAN SAWANGAN MAGELANG
}

\author{
Febri Ayuningsih ${ }^{1}$, Rifana Tia Ardana ${ }^{1}$, Lilik Kurniati ${ }^{2}$, Arbasita Endarwati ${ }^{2}$, \\ Imron Wahyu Hidayat ${ }^{2}$, Eka Sakti Wahyuningtyas ${ }^{1^{*}}$ \\ ${ }^{1}$ Program Studi Ilmu Keperawatan FIKES , Universitas Muhammadiyah Magelang \\ ${ }^{2}$ Program Studi Farmasi FIKES, Universitas Muhammadiyah Magelang \\ email:*ekasakti@ummgl.ac.id
}

\begin{abstract}
One of the subdistricts in Magelang regency which has a problem with the Diabetes Mellitus Disease in the Sawangan District, especially in the area of Sawangan Public Health Center, namely Kalangan, Gondowangi Village. So as the resolve this problem must be done various efforts of early detection in solve the problem of Diabetes Mellitus. One of the solutions to solve this problem is the dissemination as early detection and utilization of Diabetes Mellitus herbal plants. With the socialization and utilization of herbal medicinal plants on Diabetes Mellitus, it is expected that the community can pay attention to healthy lifestyles in the future, reduce the incidence of Diabetes Mellitus in the community and can take advantage of herbal treatments around the house so that people are not dependent on chemical or synthetic treatments that have side effects in the body.
\end{abstract}

Keywords: diabetes mellitus; early detection; herbal medicinal plants

\begin{abstract}
Abstrak: Salah satu Kecamatan yang ada di Kabupaten Magelang yang terdapat masalah Diabetes Mellitus yaitu Kecamatan Sawangan khususnya di wilayah kerja Puskemas Sawangan II yaitu Dusun Kalangan desa Gondowangi. Sehingga untuk mengatasi hal tersebut harus di lakukan berbagai upaya Deteksi Dini dalam mengatasi masalah Diabetes Mellitus. Salah satu dalam mengatasi masalah tersebut di lakukan sosialisasi sebagai bagian deteksi dini Diabetes Mellitus dan pemanfaatan tanaman herbal Diabetes Melitus. Dengan di adakannya sosialisasi dan pemanfaatan tanaman obat keluarga (TOGA) tentang Diabetes Melitus di harapkan mayarakat kedepannya dapat memperhatikan pola hidup sehat, mengurangi kejadian penyakit Diabetes Melitus di masyarakat dan dapat memanfaatkan pengobatan herbal di sekitar rumah agar masyarakat tidak ketergantungan dengan pengobatan kimia atau sintetik yang mempunyai efek samping dalam tubuh.
\end{abstract}

Kata kunci: deteksi dini; diabetes mellitus; tanaman obat keluarga 
Available online at https://jurnal.stmikroyal.ac.id/index.php/jurdimas

\section{PENDAHULUAN}

Penyakit Tidak Menular (PTM) menjadi penyebab utama kematian secara global. Tingkat prevalensi Diabetes Mellitus secara global pada tahun 2014 ada sekitar 8,3\% dari keseluruhan penduduk di dunia dan mengalami peningkatan pada tahun 2014 menjadi 387 juta kasus (Haskas, 2018). Sementara itu prevalensi Diabetes Mellitus di Jawa Tengah mengalami peningkatan sebesar $2,1 \%$ pada tahun 2018 dari $1,6 \%$ pada tahun 2013 (KEMENKES RI, 2019). Berdasarkan studi pendahuluan yang didapatkan di Dinas Kesehatan Kabupaten Magelang, diperoleh hasil bahwa pada tahun 2019 terdapat 6.483 orang menderita Diabetes Mellitus di Kabupaten Magelang.

Diabetes Melitus atau biasa dikenal dengan penyakit kencing manis adalah jenis penyakit degeneratif yang mengalami peningkatan setiap tahun di negara-negara seluruh dunia. Penyakit ini merupakan penyakit kelainan metabolik dengan karakteristik hiperglikemia kronis serta kelainan metabolisme karbohidrat, lemak dan protein yang diakibatkan oleh kelainan sekresi insulin, kerja insulin, maupun keduanya (Sakitri \& Kusuma, 2018). Diabetes melitus (DM) merupakan penyakit yang komplek dan secara khusus dikarakteristikkan dengan hiperglikemia kronik (Hurtado \& Vella, 2019). Peningkatan jumlah penderita Diabetes Mellitus dipengaruhi oleh umur, obesitas, kurangnya pengetahuan, kebiasaan hidup yang kurang sehat, kurangnya aktifitas fisik, pendidikan, dan status sosial ekonomi (Azriful, Nildawati, Habibi, \& Juddin, 2017).

Pada penelitian (Wahyuni, \& Alkaff, 2017) manjelaskan bahwa Proporsi Diabetes Melitus pada wanita lebih tinggi sebesar 53.2\% dibandingkan pada laki-laki sebesar $46.8 \%$, persentase Diabetes Melitus pada perempuan usia reproduksi (15-49 tahun) adalah 3,6\%. Hal ini perlu di waspadai sebab wanita dengan Diabetes Melitus memiliki resiko untuk melahirkan bayi besar.

Pengobatan yang dapat dilakukan oleh masyarakat selain menggunakan obat dari sintetik dapat juga menggunakan herbal atau tanaman obat keluarga/TOGA. Kelebihan dari pengobatan dengan menggunakan ramuan tumbuhan tradisional tersebut adalah tidak adanya efek samping yang ditimbulkan seperti yang sering terjadi pada pengobatan kimiawi (Wulandari, 2018).

(Fitriyah, Alfiyanto, Mulyadi, Wahyuningsih, \& Kismanto, 2013) Menjelaskan pada penelitiannya bahwa Daun binahong mengandung senyawa alkaolid, polifenal, dan saponin yang bersifat sebagai anti bakteri sehingga dapat dimanfaatkan sebagai obat herbal alami.

TOGA pada dasarnya adalah tanaman yang ditanam di halaman rumah, kebun atau sebidang tanah yang dimanfaatkan sebagai budidaya tanaman yang mempunyai khasiat sebagai obat dalam rangka memenuhi kebutuhan keluarga akan obat-obatan. Tanaman obat keluarga juga berfungsi sebagai pemanfaatan lingkungan di sekitar rumah dan kebun. Pemerintah melalui kementrian kesehatan secara terus-menerus mensosialisasikan tanaman obat keluarga (TOGA) dan memotifasi masyarakat agar menanam tanaman obat-obatan (Dwisatyadini, 2019).

Keberhasilan pemanfaatan TOGA dapat mempengaruhi pengetahuan masyarakat mengenai manfaat dari berbagai jenis tanaman yang berkhasiat sebagai obat, terutama tanaman obat secara empiris (Lolita, Rahmawati, Rahmah, Hasan, Afra, \& Ikrimah, 2017). 
Available online at https://jurnal.stmikroyal.ac.id/index.php/jurdimas

(Susanto, 2017) Menjelaskan strategi komunikasi terdiri dari dua aspek, yaitu: secara macro (Planned multi media strategy) dan secara mikro (Single Communication Medium Strategy) Kedua aspek tersebut mempunyai fungsi ganda, yaitu: menyebarluaskan pesan komunikasi yang bersifat informatif, persuasif dan instruktif secara sistematis kepada sasaran untuk memperoleh hasil yang optimal. Salah satu Kecamatan yang ada di Kabupaten Magelang yang terdapat masalah Diabetes Mellitus yaitu Kecamatan Sawangan khususnya di wilayah kerja Puskesmas Sawangan II yaitu dusun Kalangan desa Gondowangi. Berbagai upaya dilakukan dalam mengatasi masalah Diabetes Mellitus. Untuk mencapai keberhasilan tersebut, maka perlu dilakukan Deteksi Dini faktor resiko Diabetes Mellitus dengan pengecekan Kadar Glukosa Darah (GDS) dan screening form Diabetes Mellitus serta pemanfaatan tanaman TOGA pada masyarakat di Dusun Kalangan desa Gondowangi, Sawangan, Magelang Jawa Tengah.

\section{METODE}

Adapun Gambaran Pelaksanaan kegiatan PPMT ini dapat dilihat pada Gambar 1.

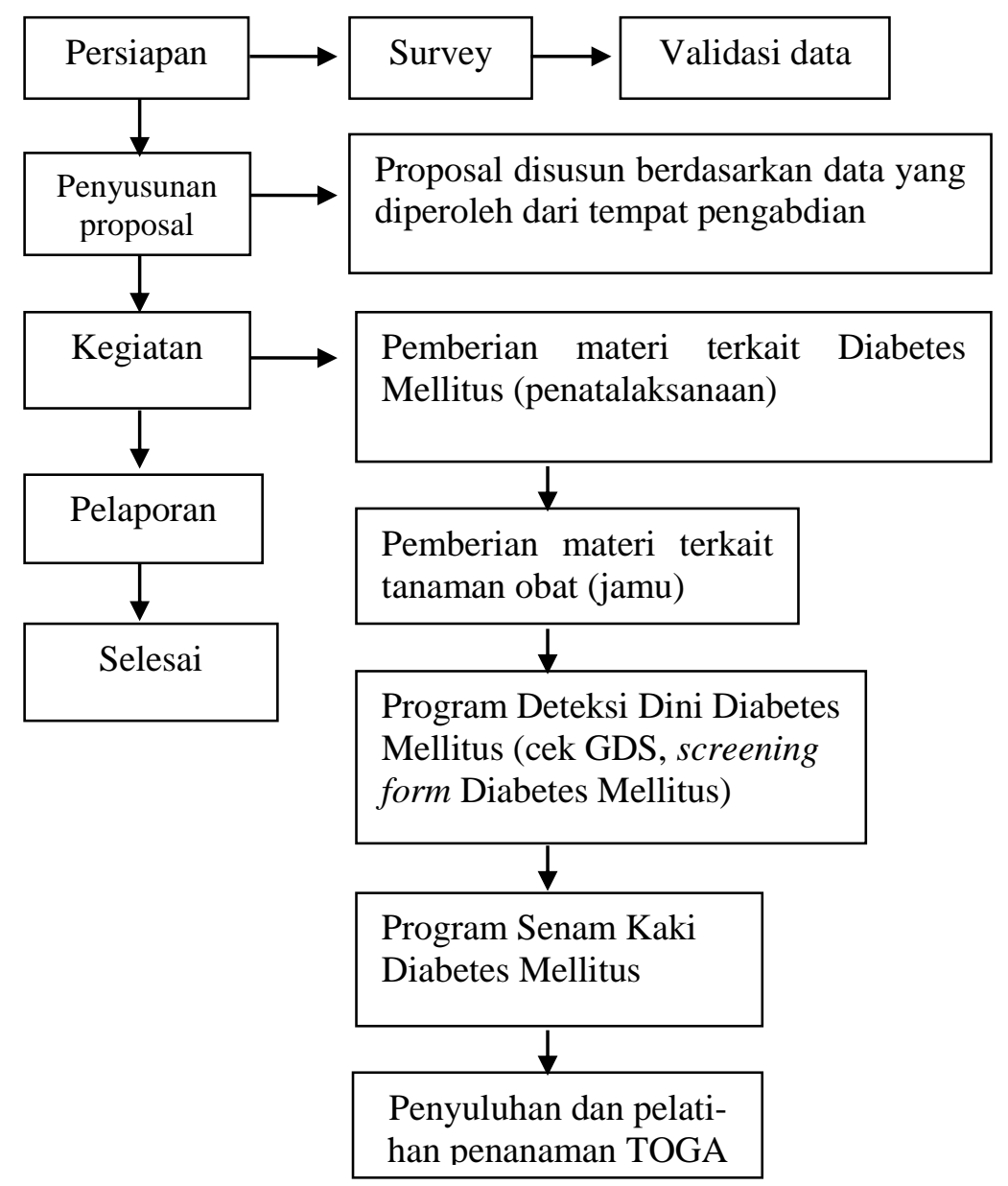

Gambar 1. Kerangka Metode Pelaksanaan Pengabdian 
Available online at https://jurnal.stmikroyal.ac.id/index.php/jurdimas

Untuk mencapai tujuan perlu diadakan kegiatan sosialisasi di Dusun Kalangan desa Gondowangi, Sawangan, Magelang Jawa Tengah, di harapkan agar masyarakat lebih mengetahui resiko tinggi Diabetes Mellitus dan pemanfaatan tanaaman TOGA untuk mengatasi permasalahan Diabetes Mellitus supaya dapat mengurangi resiko terjadinya Diabetes Mellitus. Adapun metode pelaksanaan kegiatan berupa ceramah, diskusi/tanya jawab, demonstrasi serta pelatih. Lokasi Kegiatan Progam Penga-bdian Pada Masyarakat Terpadu (PPMT) di laksanakan Di dusun Kalangan Kecamatan Sawangan Kabupaten Magelang dengan melibatkan warga desa Gondowangi khususnya warga yang mengidap penyakit Diabetes Mellitus dengan jumlah responden 20-30 orang warga. Metode dalam kegiatan PPMT ini yaitu dengan metode sosialisasi.

\section{PEMBAHASAN}

Kegiatan Program Pengabdian pada Masyarakat Terpadu (PPMT) meliputi :

\section{Pemberian materi / sosialisasi tentang Diabetes Mellitus}

Peserta progam pemberian materi atau sosialisasi tentang Diabetes Mellitus yaitu warga desa Gondowangi sejumlah 25 orang warga dilaksanakan di salah satu rumah warga desa Kalangan Gondowangi.. Tujuan dari progam yaitu menjadikan masyarakat paham dan mengerti bagaimana mengetahui faktor resiko Diabetes Mellitus. Progam pertama yaitu perkenalan tim pelaksana kepada warga desa kalangan gondowangi dan pengisian koesioner sebelum sosialisasi untuk mengetahui tingkat pengetahuan Diabetes Mellitus kepada warga. Pengisian kuesioner kepada warga berupa pertanyaan seputar ilmu pengetahuan tentang Diabetes Mellitus meningkatkan pengetahuan tentang pola hidup sehat dan meningkatkan pengetahuan masyarakat tentang tanaman herbal untuk obat Diabetes Mellitus.

\section{Pemberian materi terkait tanaman obat (jamu)}

Pada tahap ini dilakukan sosialisasi tentang pemanfaatan pengobatan tradisional terkait tanaman obat (jamu). Tujuan dari progam yaitu menjadikan masyarakat paham dan mengerti bagaimana mengetahui tentang tanaman herbal Diabetes Mellitus yang bermanfaat untuk warga desa pengetahuan tentang obat herbal yang digunakan untuk mengatasi Diabetes Mellitus sebagai alternatif pengganti obat kimia yang mempunyai efek samping. Materi yang di sampaikan yaitu peman-faatan tanaman herbal untuk Diabetes Mellitus, khasiat tanaman herbal, memberikan pengetahuan bagaimana cara memanfaatkan tanaman herbal untuk pengobatan Diabetes Mellitus. Peserta sosialisasi berjumlah 22 orang warga di Desa Kalangan Gondowangi.

\section{Program Deteksi Dini Diabetes Melli- tus (cek GDS, screening form Diabetes Mellitus)}

Tahap ini dilakukan Pengecekan kadar gula darah kepada warga desa Kalangan yang hadir di tempat pelaksanaan. Pengecekan kadar gula darah untuk mengetahui kadar gula darah normal pada warga. Pengecekan kadar gula darah di lakukan oleh mahasiswa perawat dan pengambilan data hasil kadar gula darah (GDS) pada warga. Hasil yang didapat mengetahui kadar gula darah dalam sewaktu dan Mampu mengetahui normal gula darah warga di desa Kalangan Gondowangi. Hasil yang di dapat 
Available online at https://jurnal.stmikroyal.ac.id/index.php/jurdimas

dari hasil pengecekan kadar gula darah pada warga ibu-ibu PKK menunjukan mayoritas kadar gula darah yang diperoleh warga gula darah warga normal dengan rata-rata $70-140 \mathrm{mg} / \mathrm{dl}$. Hanya beberapa warga yang mengalami kadar gula darah yang tinggi. Di lihat dari hasil yang di dapat warga yang mempunyai gula darah normal mengikuti pola makan yang sederhana dengan jarang mengom-sumsi makanan siap saji. Kadar gula darah yang tinggi salah satu warga mengatakan bahwa ada riwayat keluaga yang menderita Diabetes Mellitus.

\section{Program Senam Kaki Diabetes Melli- tus}

Program Pengabdian Pada Masyrakat Terpadu (PPMT) selanjutnya yaitu melaksanakan kegiatan senam kaki Diabetes Mellitus kepada warga. Pada tahap ini pelaksanaan yang di perlukan berupa proyektor untuk menampilkan video berupa senam kaki Diabetes Mellitus agar warga dapat melihat dan mengikuti intruksi mahasiswanya, kertas koran, kursi untuk senam Diabetes Mellitus, dan mahasiswa yang telah terlatih dalam melakukan senam Diabetes Mellitus.

Pelaksanan senam kaki Diabetes Mellitus dipandu oleh tim pelaksana dengan warga mengikuti instruksi tim dan pelaksanaaan selama senam kaki Diabetes Mellitus selama kurang lebih 10 menit setiap tahap senam kaki Diabetes Mellitus. Pada tahap ini senam kaki Diabetes Mellitus di lakukan beberapa kali di selingi dengan istirahat dan cengkrama warga sekitar setiap melakukan senam kaki Diabetes Mellitus. Diharapkan hasil yang di dapat warga dapat menghafal setiap gerakan senam dan dapat melakukan tanpa melihat tayangan video dan diharapkan dapat memberikan manfaat dan dapat mengurangi penderita Diabetes Mellitus. Serta pembagian video senam kaki Diabetes Mellitus bagi warga untuk menghafalkan dan dapat mempraktekkannya di rumah masing-masing ataupun diberbagai kegiatan yang di laksanakan oleh warga.

\section{Penyuluhan dan pelatihan penanaman TOGA}

Pada tahap ini diawali dengan mengundang warga dan mengisi sosialisasi terkait TOGA setelah pelaksanaan yang di adakan warga ibu-ibu yaitu pertemuan rutin PKK di desa Kalangan. Selanjutnya di lakukan sesi tanya jawab oleh peserta. Tahap selanjutnya yaitu penanaman TOGA kepada warga masyarakat desa Kalangan, Gondowangi. Pelaksanakan kegiatan Pemberian tanaman TOGA kepada warga untuk di tanam di pekarangan rumah masingmasing. Tanaman TOGA yang di berikan berupa tanaman yang memiliki khasiat untuk mengatasi Diabetes Mellitus. Diharapkan warga dapat memanfaatkan tanaman TOGA dan dapat memanen tanaman TOGA untuk di manfaatkan obat herbal Diabetes Mellitus dan untuk mengatasi kadar gula darah yang tinggi.

Pada program sosialisasi terkait Diabetes Mellitus dan Sosialisasi terkait tanaman tradisional serta pemanfaatan TOGA untuk mengatasi Diabetes Mellitus, di lakukan pretest maupun posttest untuk mengetahui tingkat pengetahuan. Tingkat pengetahuan Diabetes Mellitus dan tanaman tradisional serta TOGA untuk mengatasi Diabetes Mellitus mengalami peningkatan (Tabel 1). 
Available online at https://jurnal.stmikroyal.ac.id/index.php/jurdimas

Tabel 1. Nilai Pre-test dan Post-test

\begin{tabular}{lcc}
\hline \multicolumn{1}{c}{ Tema } & Pretest & Postest \\
\hline Pengetahuan tentang Diabetes Mellitus & $30 \%$ & $80 \%$ \\
\hline $\begin{array}{l}\text { Pengetahuan tentang tanaman tradisional untuk mengatasi Diabe- } \\
\text { tes Mellitus }\end{array}$ & $25 \%$ & $80 \%$ \\
\hline
\end{tabular}

Pada saat dilakukan evaluasi yaitu dilakukan posttest berupa pengisian kuisoner di bandingkan dengan dilakukan pretest saat belum di lakukan sosialisasi. Hasil dari sosialisasi ini yaitu Masyarakat mampu mengetahui apa itu Diabetes Mellitus, Masyarakat mengetahui tanda dan gejala dari penyakit Diabetes Mellitus, serta Masyarakat mampu mengetahui faktor penyebab dan makanan yang sehat agar terhindar dari Diabetes Mellitus.

Terlepas dari hal tersebut, terdapat faktor pendukung dan hambatan dalam pelaksanaan kegiatan. Dukungan dari pihak kepala desa, kepala dusun Kalangan dan ketua kader posyandu desa Gondowangi setempat serta antusis warga dalam mengikuti kegiatan kami khususnya ibu-ibu warga desa kalangan. Kepada kepala desa, kepala dusun Kalangan dan ketua kader posyandu desa Gondowangi yang telah memerikan izin untuk melaksanakan Progam Pengabdian Pada Masyarakat Terpadu (PPMT) di desa Kalangan Gondowangi Sawangan Magelang.

Keantusiasan warga dengan ikut hadir pada kegiatan kami karena warga juga menyadari pentingya tentang pengetahuan Diabetes Mellitus, warga di harapkan warga dapat mengatasi Diabetes Mellitus untuk, pemanfaatan obat herbal di komsumsi yang memberikan khasiat dan tidak menimbulkan efek samping dari mengomsumsi obat herbal dari pada mengomsumsi obat kimia yang dapat menimbulkan efek samping dan pemanfaatan tanaman TOGA di pekarangan rumah warga agar sewaktuwaktu di butuhkan tinggal memanen dan memanfaatkan tanaman tersebut untuk pengobatan Diabetes Mellitus.

\section{SIMPULAN}

Dengan demikian, secara keseluruhan tujuan dari Progam Pengabdian Pada Masyarakat Terpadu (PPMT) di desa Kalangan Gondowangi Sawangan Magelang telah tercapai dilihat dari tingkat pemahaman warga tentang resiko Diabetes Mellitus, faktor resiko Diabetes Mellitus, dan pengetahuan tentang pemanfaatan tanaman herbal (TOGA) mengalami peningkatan dengan menerapkan hasil hasil pretest dan posttest.

\section{UCAPAN TERIMA KASIH}

Ucapan terima kasih disampaikan kepada Lembaga Pengembangan Penelitian dan Pengabdian Masyarakat (LP3M) Universitas Muhammadiyah Magelang yang telah memberikan support atas keberlangsungan kegiatan PPMT ini, ucapan terimakasih yang sama juga kepada masyarakat desa Kalangan Gondowangi Sawangan Magelang atas dukungan dan kerjasama yang telah diberikan. 
Available online at https://jurnal.stmikroyal.ac.id/index.php/jurdimas

\section{DAFTAR PUSTAKA}

Azriful, A., Nildawati, N., Habibi, H., \& Juddin, D. R. (2018). Hubungan Tingkat Pengetahuan Faktor Risiko DM Dengan Status DM Pada Pegawai Negeri Sipil UIN Alauddin Makassar. Al-Sihah: The Public Health Science Journal, 10(1).

Dwisatyadini, M. (2019). Pemanfaatan Tanaman Obat Untuk Pencegahan Dan Pengobatan Penyakit Degeneratif. (April).

Fitriyah, N., Alfiyanto, M. A., Mulyadi, M., Wahyuningsih, N., \& Kismanto, J. (2013). Obat Herbal Antibakteri Ala Tanaman Binahong. Jurnal Kesehatan Kusuma Husada.

Haskas, Y. (2018). Pelatihan Pengelolaan Makan Dengan 3J Pada Penderita Dm Beserta Keluarganya Di Kecamatan Simbang Kabupaten Maros. Jurnal Dedikasi Masyarakat, 2(1), 11. https://doi.org/10.31850/jdm.v2i 1.358

Hadi, E. E. W., Widyastuti, S. M., \& Wahyuono, S. (2016). Keanekaragaman Dan Pemanfaatan Tumbuhan Bawah Pada Sistem Agroforestri Di Perbukitan Menoreh, Kabupaten Kulon Progo (Diversity and Untilization of Understorey in Agroforestry System of Menoreh Hill, Kulon Progo Regency). Jurnal Manusia dan Lingkungan, 23(2), 206-214.

Hurtado, M. D., \& Vella, A. (2019). What is type 2 diabetes? Medicine (United Kingdom), 47(1), 10-15. https://doi.org/10.1016/j.mpmed.
2018.10.010

Ikaditya, L. (2016). Hubungan Karakteristik Umur dan Tingkat Pendidikan Terhadap Pengetahuan Tentang Tanaman Obata Keluarga (TOGA). Jurnal Keshatan Bakti Tunas Husada, 16(1) 171-176.

KEMENKES RI (2019) 'Hari Diabetes Sedunia Tahun 2018', Pusat Data dan Informasi Kementrian Kesehatan RI, pp. 1-8.

Lolita, L., Rahmawati, A., Rahmah, A., Hasan, E. A., Afra, F. Y., \& Ikrimah, I. (2018). Pengaruh Promosi Kesehatan Terhadap Pengetahuan Toga Untuk Hipertensi di Sumberagung Jetis Bantul. PHARMACY: Jurnal Farmasi Indonesia (Pharmaceutical Journal of Indonesia), 14(2), 236-246.

Pusthika, I. O., Tjahjono, K., \& Nuggetsiana, A. (2011). Pengaruh Frekuensi Konseling Gizi dan Gaya Hidup terhadap Indeks Massa Tubuh, Lingkar Pinggang, Tekanan Darah, dan Glukosa Darah pada Penderita Diabetes Mellitus (Doctoral dissertation, Faculty of Medicine).

Sakitri, G., \& Kusuma, R. (2018). Pelatihan Deteksi Dini Berdasarkan Faktor Resiko Diabetes Melitus Kader Dukuh Sonosewu. Link, 14(1), 41. https://doi.org/10.31983/link.v1 $4 \mathrm{i} 1.3284$

Susanto, A. (2017). Komunikasi dalam Sosialisasi Tanaman Obat Keluarga (TOGA) di Kecamatan Margadana. Parapemikir: Jurnal Ilmiah Farmasi, 6(1).

Wahyuni, S., \& Alkaff, R. N. (2013). Diabetes Mellitus pada 
Available online at https://jurnal.stmikroyal.ac.id/index.php/jurdimas

Perempuan Usia Reproduksi di Indonesia Tahun 2007.

Indonesian Journal of
Reproductive Health, 3(1), 4651.

Wulandari, R. L. (2018). Pemanfaatan Tanaman Obat Keluarga (Toga) Untuk Pengobatan Diabetes Melitus. Abdimas Unwahas, 3(1)., 30-32.

Worang, V. H., Bawotong, J., \& Untu, F. M. (2013). Hubungan pengendalian diabetes mellitus dengan kadar glukosa darah pada pasien diabetes mellitus di rsud manembo nembo bitung. Jurnal keperawatan, 1(1).

Zuercher, E., Diatta, I. D., Burnand, B., \& Peytremann-Bridevaux, I. (2017). Health literacy and quality of care of patients with diabetes: A cross-sectional analysis. Primary care diabetes, 11(3), 233240. 